\title{
CASE REPORT: CELLULAR THERAPY TREATMENT IN CHRONIC WOUND OF PATIENTS WITH CREST SYNDROME
}

\section{Bianca P. Patrús*, Paula Tavares Colpas, Paulo C. M. Alves, Isadora F. Custódio, Mariana Bergman, Maria Beatriz Puzzi, Carolina Caliari-Oliveira.}

\begin{abstract}
Patients with scleroderma, especially those with CREST syndrome, are predisposed to develop chronic skin wounds. These wounds are difficult to treat and directly affect the quality of life of these patients. Thus, the present study evaluated the use of autologous fibroblasts for the treatment of wounds caused by calcium deposition typical of CREST syndrome pathology.
\end{abstract}

\section{Key words:}

cellular therapy, cronic ulcers, CREST syndrome.

\section{Introduction}

Scleroderma is characterized by two types: diffuse and CREST syndrome. CREST is an acronym that describes the main symptoms and signs of the disease: calcinosis, Raynaud's phenomenon, esophagopathy, sclerodactyly and telangiectasia. Calcinosis is characterized by the deposition of calcium in the dermis, hypodermis or wounds. This deposition results in a continuous inflammatory reaction that promotes the development of chronic wounds. Thus, the aim of this study was to report a case of cell therapy for the treatment of chronic wound in patient with CREST syndrome.

\section{Results and Discussion}

A 71-year-old female patient with CREST syndrome, diagnosed 32 years ago, manifested Raynaud's phenomenon, sclerodactyly, calcinosis, and talangectasia. For 28 years, she has presented chronic wounds of difficult treatment, with a history of recurrent infections of these lesions, including hospitalization for antibiotic therapy. Medications included colchicine, bosentan, sildenafil, marevan, azathioprine, concore and aspirin. Regarding the serological markers, the patient presented anti-centromere antibody and ANA positive and Anti-SCL-70 negative. Physical examination revealed wound in the right lower limb with calcinosis. The lesion was on average $5.4 \mathrm{~cm}^{2}$. Cell therapy was performed with an application of $0.6 \times$ $10^{6}$ fibroblasts cultured from an abdominal skin flap. The ulcer was followed for a period of 7 months. Reduction of ulcer size was observed from the first week after application of the cells. Two months after cell therapy there was a $77.3 \%$ decrease in ulcer size. Four months after cell therapy, the ulcer was completely reepithelialized. After 7 months of the cellular therapy no recurrence of the treated wound was observed, as well as side effects.

In addition to its classic manifestations CREST syndrome has several other characteristics that affect patient's quality of life. Chronic wounds caused by calcium deposit are an example of this. The current gold standard treatment for these wounds is the debridement procedure, a painful process, depending on both the patient's condition and the extent of the wound. Hence, the cellular therapy may fulfill the necessity to find new treatments for this type of wounds.

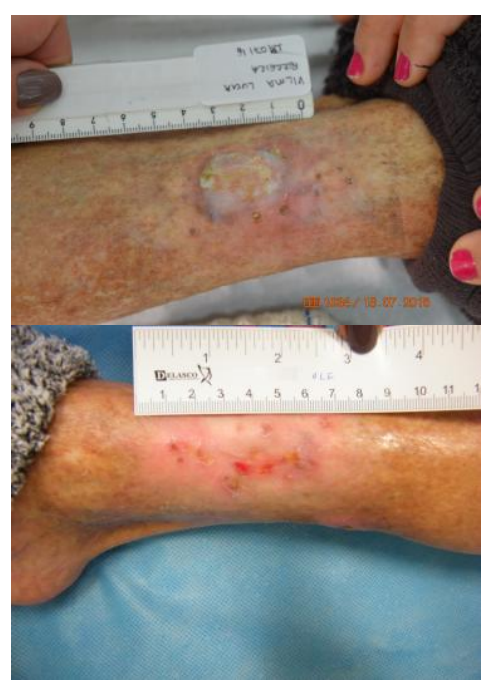

Figure 1. Overall aspect of the wound at the beginning (top image day 0 ) an the end (bottom image after 120 days) of treatment.

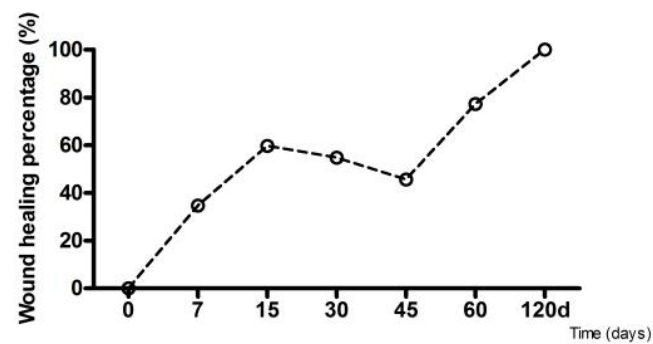

Figure 2. Percentage of wound area healed over treatment time in days.

\section{Conclusions}

The treatment of wounds in patients with CREST syndrome is still a challenge GIVEN the little understanding about calcium deposition and chronic wound formation. Cell therapy may be a safe and effective alternative for the treatment of skin wounds in these patients.

\section{Acknowledgement}

Thanks to FAPESP, the project's financing body.

AL-NAJJAR, Mahmoud; JACKSON, Mark J.. Non-healing leg ulcers in a patient with dystrophic calcification and crest syndrome: a challenging clinical case. International Wound Journal, [s.l.], v. 8 , n. 5 , p.537-541, 9 ago. 2011. Wiley-Blackwell. VALENZUELA, Antonia; CHUNG, Lorinda. Calcinosis. Current Opinion In Rheumatology, [s.1.], v. 27, n. 6, p.542-548, nov. 2015. Ovid Technologies (Wolters Kluwer Health) ENOCH, Stuart et al. Dystrophic calcification as a cause for non healing leg ulcers. International Wound Journal, [s.l.], v. 2, 